\title{
"Ring-Like Mass" Surrounding the Cervix of a Primary Incisor. Report of a Challenging Case
}

\author{
Nikoleta Papageorgiou1, Efstathios Pettas², Maria Georgaki ${ }^{3}$, Nikolaos G. Nikitakis ${ }^{4}$ \\ ${ }^{1}$ School of Dentistry, National and Kapodistrian University of Athens, Greece, nicolerfms@gmail.com. \\ ${ }^{2}$ Department of Oral Medicine \& Pathology and Hospital Dentistry, School of Dentistry, National and Kapodistrian University \\ of Athens, Greece, stathis.pettas12@gmail.com. \\ ${ }^{3}$ Department of Oral Medicine \& Pathology and Hospital Dentistry, School of Dentistry, National and Kapodistrian University \\ of Athens, Greece, marlgeorgaki@gmail.com. \\ ${ }^{4}$ Department of Oral Medicine \& Pathology and Hospital Dentistry, School of Dentistry, National and Kapodistrian University \\ of Athens, Greece, nnikitakis1@yahoo.com.
}

\author{
Corresponding Author: \\ Maria Georgaki \\ Department of Oral Medicine \& Pathology and Hospital Dentistry \\ School of Dentistry, University of Athens \\ 2 Thivon St., Goudi 11527, Athens \\ Greece \\ Phone: +30 210 7461304; +30 6974785099; +1 6679104297 \\ E-mail: marlgeorgaki@gmail.com
}

\begin{abstract}
Background: Several lesions of diverse origin may be detected in the oral cavity of children, affecting the oral mucosa, jaws, or teeth. In equivocal cases, their clinicopathologic features may show considerable overlap with various entities. We present a case of a "ring-like" hard mass around the cervical area of a primary tooth in a child and discuss the diagnostic challenges. Methods: A 2.5 year-old girl was presented by her mother for evaluation of a painless left first primary lower incisor lesion, first noticed 5 months ago. Medical history was unremarkable, while previous injury or other incident could not be recalled by the patient's mother. Clinical examination and a periapical radiograph were performed.

Results: The clinical examination revealed a yellowish, non-removable, hard in consistency, cylindrical mass, completely surrounding the cervical area of the left first primary lower incisor. A periapical radiograph was performed, revealing a cylindrical radiopacity of mild intensity encasing the tooth cervix and a diagnosis of a foreign body inserted around the tooth was made. Regular follow-up appointments were attended for the next 4 years in which mild but progressive gingival recession, revealing a larger part of the ring-like structure was observed. At age of 6 , the tooth was extracted and a cylindrical structure was detached from the tooth, confirming its nature as a foreign body.

Conclusions: A foreign body surrounding the cervix of a tooth eventually becoming inseparable may cause a peculiar clinical and radiographic appearance and provoke diagnostic difficulties, especially in the lack of a relevant history.
\end{abstract}

Keywords: foreign bodies; foreign objects; child; pediatric dentistry; tooth abnormalities.

\author{
Accepted for publication: 29 December 2021 \\ To cite this article: \\ Papageorgiou N, Pettas E, Georgaki M, Nikitakis NG. \\ "Ring-Like Mass" Surrounding the Cervix of a Primary Incisor. Report of a Challenging Case \\ J Oral Maxillofac Res 2021;12(4):e5 \\ URL: http://www.ejomr.org/JOMR/archives/2021/4/e5/v12n4e5.pdf \\ doi: $10.5037 /$ jomr.2021.12405
}




\section{INTRODUCTION}

Several lesions of diverse origin may be detected in the oral cavity of young children involving the oral mucosa, jaws, and/or teeth. Tooth abnormalities in children may be due to a wide spectrum of causative factors, from developmental defects to injuries, associated - or not - with a foreign body (FB).

Children tend to place foreign objects in their mouth with the risk of accidental impaction, ingestion, or aspiration [1]. Compared to other anatomic locations, the oral cavity - as a part of the gastrointestinal tract may be a predominant site of involvement [1]. A study of 319 cases of oral trauma revealed that tumble was the main cause, accounting for almost $50 \%$ of cases, while $22 \%$ of injuries were associated with the use of a foreign object [2]. Palate was the most frequent oral site to be affected by a FB, while toothbrush was the most common object to be implicated in such injuries $(31 \%)$ [2]

Interestingly, it has been suggested that children tend to bite an object using a tooth affected by dental caries in order to get relief from pain, a habit that could lead to its implantation to the child's tooth [ $\underline{3}]$ or even the surrounding soft tissues. Other factors associated with these parafunctional habits could include psychological or even psychiatric conditions that may occasionally be seen in juveniles [4].

In equivocal cases, the clinicopathologic features of a FB-associated lesion may show significant overlap with other entities leading to diagnostic dilemmas. Herein, we report a case of a "ring-like mass" around the cervical area of a primary tooth in a child and discuss the diagnostic challenges and the management.

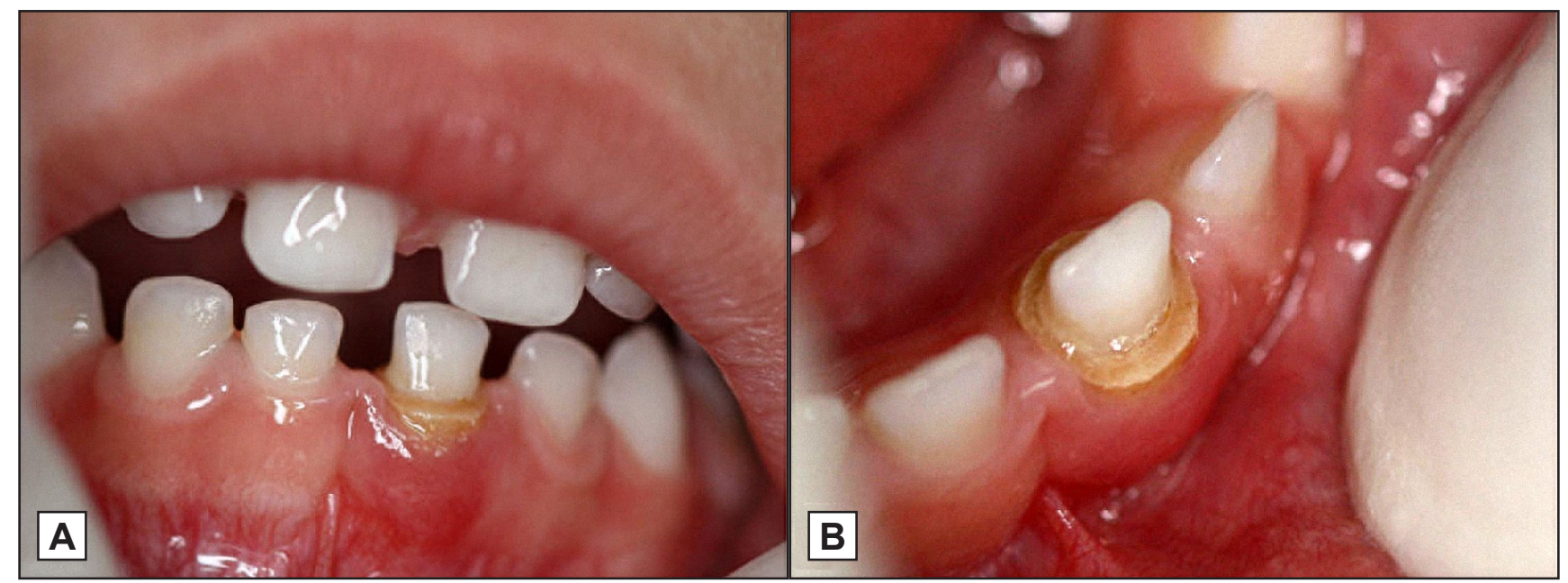

\section{CASE DESCRIPTION AND RESULTS}

A 2 years and 8 months old Caucasian girl presented by her mother on May 4, 2015, in an Oral Medicine Clinic in Athens, Greece, for evaluation of a painless lesion involving the left mandibular primary central incisor, first noticed approximately one year before. According to the mother, the affected tooth was "different in appearance compared to the others", although the defect was asymptomatic and had not increased in size or changed otherwise. Despite careful questioning, neither previous trauma nor other incident in the area could be recalled. The medical history was unremarkable and no medications were used. On clinical examination, a yellowish-brownish lesion, hard in consistency and cylindrical in shape, was firmly attached and completely surrounding the cervical area of the left mandibular primary central incisor (Figure 1). Although no periodontal pocket or tooth mobility were noticed, a mild gingival recession and slight haemorrhage upon probing were seen. The tooth was not affected by dental caries and was tested positive for pulp vitality. The cylindrical structure was strongly adhered to the root's surface and could not be removed using an ultrasound device. The remaining dentition was free of any abnormalities or discolorations and the rest of the oral examination did not reveal any pathologic findings. A periapical radiograph was suggested, but the mother - due to child's very young age - was reluctant to consent. A close follow-up was recommended.

The patient returned after 14 months; the lesion remained asymptomatic, but a gradual "lowering of the gums" was reported. Indeed, on clinical examination, increased gingival recession was seen,

Figure 1. Clinical examination at the time of the initial visit (at age 2 years and 8 months).

A and $\mathrm{B}=$ yellowish-brownish cylindrical mass, hard in consistency, completely surrounding the cervical area of the left mandibular primary central incisor. 
revealing a larger part of the "ring-like" structure (Figure 2A). At this time, a periapical radiograph was performed, displaying a cylindrical radiopacity of mild intensity, surrounding the tooth cervix and extending approximately $2 \mathrm{~mm}$ apically; alveolar bone loss, appearing as cup-like resorption, was also seen (Figure 2B). No abnormalities within the pulp chamber or the middle and apical portion of the root were noticed, ruling out rare teeth developmental anomalies, such as dentin dysplasia (DD) type Id; hypercementosis (HC) was also excluded based on the localized nature and geometric shape of the radiopacity. Instead, the perfectly cylindrical morphology of the radiopaque structure along with the clinical appearance and course essentially confirmed the provisional diagnosis of FB entrapment in the cervical area of the tooth. Considering the inability to conservatively remove the FB by simple use of ultrasound device or other tools without damaging or extracting the tooth, the fact that the mother refused the extraction of the tooth or any other invasive treatment due to child's very young age, as well as the total lack of symptoms, the patient was advised to attend regular follow-up appointments until the expected time of permanent incisor eruption. The mother and child were also advised to apply diligent oral hygiene in the area of the affected tooth and to promptly report the development of any potential symptoms or other changes.

Nine months later, no significant changes were noticed, besides a slightly more apparent gingival recession. For the next 18 months, no further changes were noticed, except an occasional mild and transient sensitivity in the area. At the age of 6 years and 3 months, the patient returned for tooth extraction; clinically, the cylindrical FB was more apparent (and more brownish in hue) and the tooth has developed mild mobility. Radiographically, increased alveolar bone resorption around the primary tooth root was seen, as well as normal eruption process of the left central permanent incisor, the root development of which has reached two thirds to three quarters (Figure 3A). A simple extraction of the primary tooth was performed and the intact crown of the permanent tooth was revealed intraoperatively (Figure 3B). The extracted tooth, along with periapical soft tissues, was submitted for histopathologic assessment. On gross examination, the cylindrical structure was detached with difficulty from the tooth (only when significant force was applied vertically towards the thinner and resorbed apical portion of the root), confirming its nature as a FB (Figure 4), while microscopic examination of the periapical soft tissues showed granulation and fibrous connective tissue with focal areas of chronic inflammation and scattered inert odontogenic epithelial rests. Considering the clinical and radiographic appearance and macroscopic examination, the final diagnosis of a rubber "ring-like" FB was rendered, possibly corresponding to a toy part that was accidentally misplaced by the patient, when she was a toddler. Uneventful eruption of the intact left mandibular permanent central incisor was confirmed at 1-month and 1-year (Figure 5) follow-up appointments.

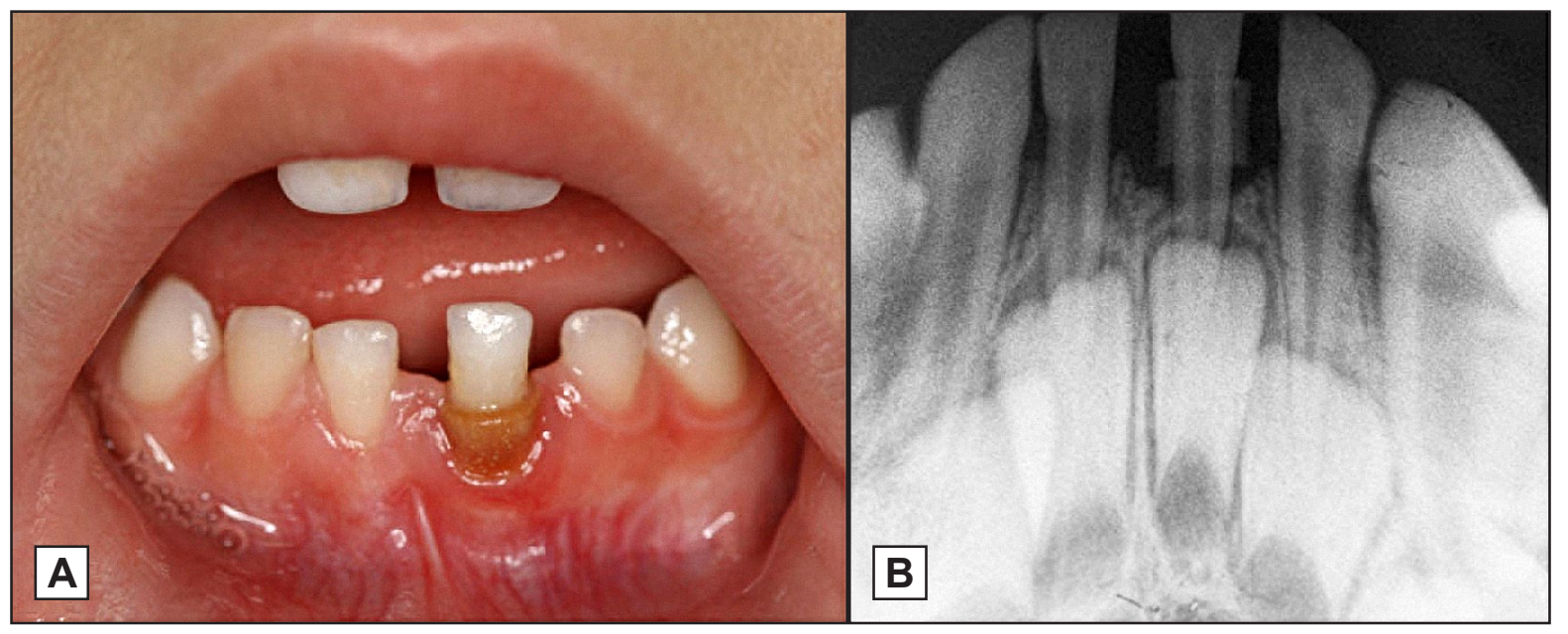

Figure 2. Second examination (at age 3 years and 10 months).

$\mathrm{A}=$ Progressive gingival recession, revealing a larger part of the brownish "ring-like" structure around the cervical area of the involved tooth, which appears to be slightly extruded.

$\mathrm{B}=$ Periapical radiograph showing a cylindrical structure appearing as radiopacity of mild intensity surrounding the tooth cervix and extending approximately $2 \mathrm{~mm}$ apically.

A cup-like resorption of the alveolar bone, limited to the area of the left first primary central incisor, is also seen, in the absence of any abnormalities within the pulp chamber or the periapical area of the tooth. 


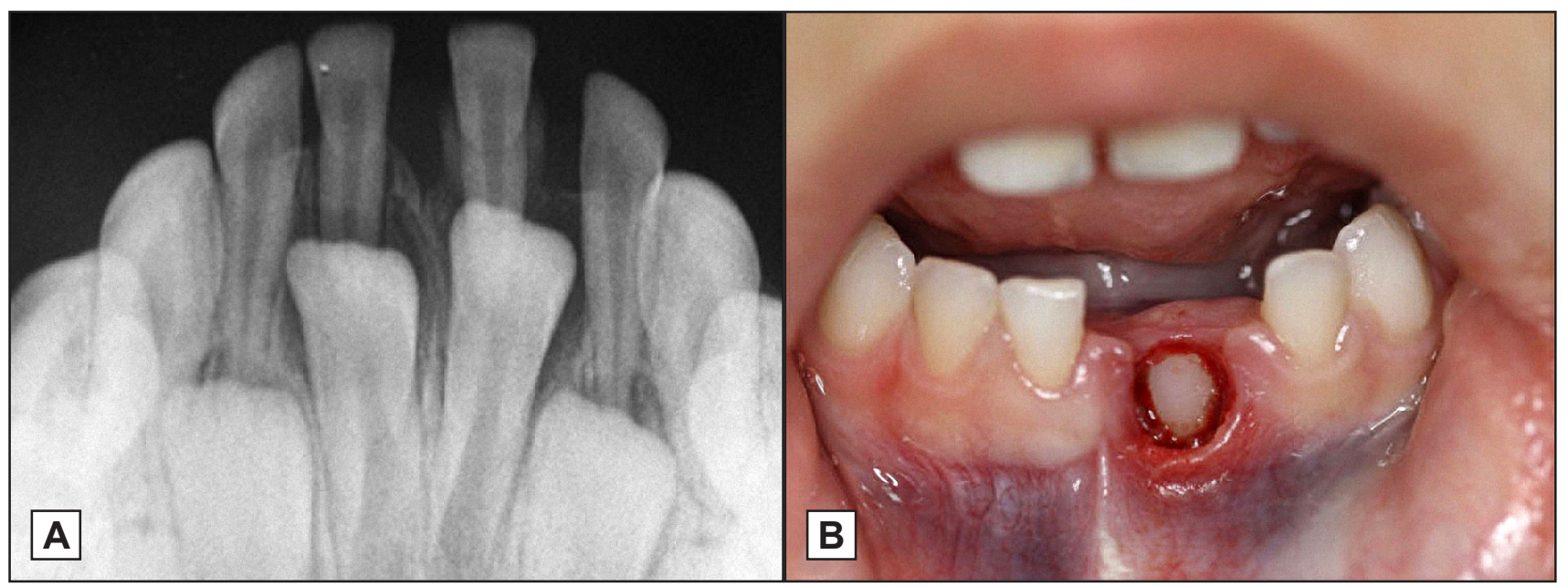

Figure 3. Pre-extraction examination (at age 6 years and 3 months).

$\mathrm{A}=$ Preoperative radiographic evaluation showed continuous alveolar bone resorption.

$\mathrm{B}=$ Intraoperatively, the intact crown of the permanent successor tooth was revealed.

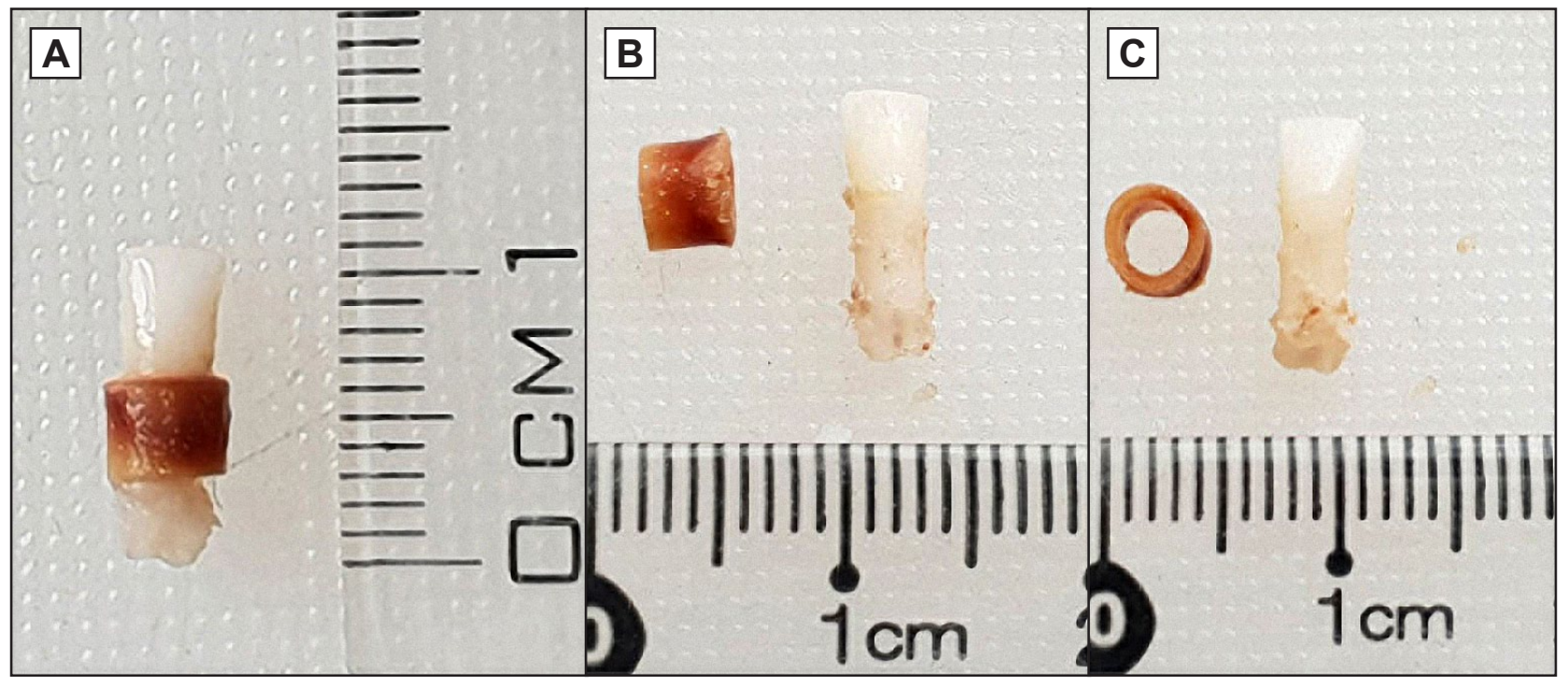

Figure 4. Gross examination of the extracted tooth. A brownish cylindrical structure of approximately $0.4 \mathrm{~cm}$ in length and diameter, which was strongly adhered to the root's surface, was detached with difficulty, confirming its nature as a hollow foreign body.

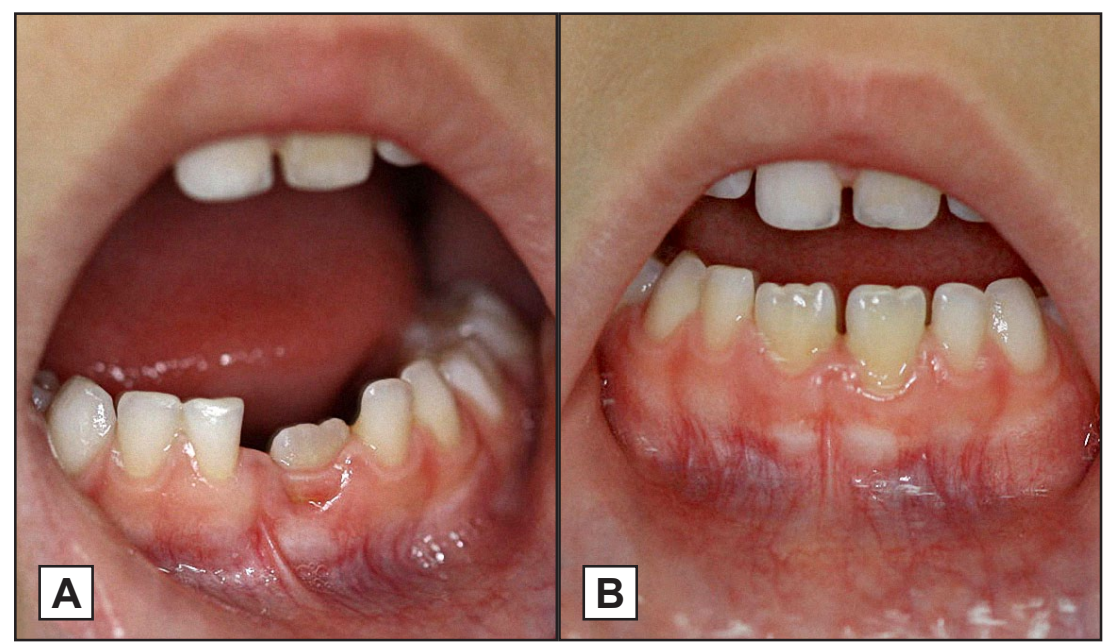

Figure 5. Uneventful eruption of the left mandibular permanent central incisor.

$\mathrm{A}=1$-month follow-up appointment.

$\mathrm{B}=1$-year follow-up appointment. 


\section{DISCUSSION}

Considering young children's habit of placing foreign objects in their mouth, entrapment of a FB in oral and maxillofacial soft or, less commonly, hard tissues is not uncommon. Regarding soft tissues, Rocha et al. [5] justified the predominance of hard palatal mucosa as a site of FB insertion due to the habit of sucking an object; interestingly, in 2 out of 3 cases reported in this paper, the lesion was initially confused with a neoplastic process and, therefore, an incisional biopsy was suggested [5]. A foreign object impacted in hard palate, radiographically mimicking an odontoma has been documented [6]. Other oral mucosal areas can be similarly affected, including cases of toothbrush entrapment in the buccal region [7]. In terms of hard tissues, few cases of FB entrapment inside a child's tooth have been reported in the literature, involving the pulp chamber and/or root canals. Gujjar et al. [8] reported two children with a broken office pin and pencil tip, respectively, inserted into their primary molars, while impaction of more uncommon foreign objects, such as screws [9], have also been described. On the other hand, lodgement of a circular foreign object in the cervix of a tooth has been only rarely reported [10-14]. FBs surrounding teeth may extend to the periodontal tissues, causing FB gingivitis [15]. A foreign object could be also entrapped in the periodontal tissues without directly affecting the regional teeth. Incisors seem to be the most common teeth involved [11-13]. The majority of such FBs were made of plastic, while the most "dangerous" object detached was a metal ring [10]. The origin of entrapped FB is variable including dental and orthodontic appliances, toys or other random objects. Intriguingly, an elastic FB, such as an orthodontic band, could be found in the apical area of a tooth, regardless of the site of initial application [16]. As onychophagia is a relatively common habit of young patients, fingernail fragments seem to be a frequent finding [10].

Even though most of these FBs cause an innocent clinical appearance, more alarming cases associated with a reactive lesion have also been published [14]. From a diagnostic standpoint, although a provisional diagnosis of a FB is commonly given, the differential diagnosis could include other entities, such as HC [10]. Further, a FB implemented to the cervix of a tooth may occasionally bear resemblance to a wide spectrum of developmental teeth abnormalities. In the case presented here, the lesion seemed to be irremovable from the involved tooth. Additionally, the patient's mother did not recall a history of trauma or any other related event potentially affecting the anterior mandibular region. Although the rest of the dentition was normal, and the appearance of the defect was peculiar, developmental teeth abnormalities and $\mathrm{HC}$ were considered at the initial visit and before a radiographic examination provided more information about the shape and location of the structure enveloping the cervical part of the root.

Among alterations in the shape of teeth, $\mathrm{HC}$ or cemental hyperplasia is a non-neoplastic deposition of cementum on the root surface of a tooth [17]. Patients diagnosed with $\mathrm{HC}$ are usually young to middle-aged adults $[\underline{18}, 19]$. Gender predilection still remains a controversial issue, as few - but not all - studies support a female predominance $[\underline{18}, 19]$. $\mathrm{HC}$ is commonly generalized affecting multiple teeth [19], among which the mandibular teeth seem to be more susceptible compared to their maxillary counterparts $[18,19]$. Molars and premolars seem to be affected more frequently than incisors $[18,19]$. HC lacks distinctive clinical features or symptoms $[\underline{18}, \underline{19}]$. Radiographically, it demonstrates a thickening of the root's surface, which usually involves the periapical region and may be clearly visible after the extraction of the defective tooth [17-19]. HC may be idiopathic or associated with various local factors, such as adjacent chronic infection, occlusal trauma and unopposed teeth [17]. Many authors support that patients suffering from certain systemic conditions, such as Paget's disease, arthritis, calcinosis, and thyroid goiter, are placed at high risk of $\mathrm{HC}$ development [17]. Our patient was free of any local or systemic predisposing factor for HC. Some of the clinical characteristics of our case could be considered as compatible with the overall findings seen in $\mathrm{HC}$, including the excess of yellowish hard tissue on the root surface, which could be extending from the apical area towards the cementoenamel junction of the tooth giving this uncharacteristic clinical appearance. Also, periodontal probing and local application of ultrasound did not reveal evident separation between the lesion and the root surface, suggesting that the former could be deriving from the cementum. Thus, the possibility that this defect could represent a manifestation of localized $\mathrm{HC}$ affecting the cervical area of the child's primary tooth was considered. However, a radiodensity involving all of the root surface - mostly the periapical area - and in continuity with the dental structure would be the expected radiographic finding in this scenario.

Among alterations in the structure of teeth, DD is a hereditary disorder of dentin formation, which follows an autosomal dominant pattern of inheritance [20]. Both primary and permanent dentitions can be 
affected [21]. Although the colour of the involved teeth is usually normal, cases with a slightly opalescent brown or blue discoloration have rarely been described [21]. DD type I (DD-I) commonly lacks clinically evident manifestations, while tooth mobility is usually the first sign [20]. Among DD-I variants, type Id shows some similarity with our case; in this condition, commonly a pulp stone within the root canal makes the coronal area of the root appearing bulbous [22]. Interestingly, similar dentinal alterations may be associated with other systemic diseases, such as tumoral calcinosis [23]. The clinical examination in our case revealed a "mass" with welldefined sharp edges at the level of the cementoenamel junction in continuity with the root surface rather than a bulbous enlargement as seen in DD type Id. Also, the involved tooth did not display mobility, while the remainder of the dentition was normal. Additionally, our patient was free of any systemic disorder. Based on all the above, the possibility that this defect could exhibit an atypical, localized DD type Id developmental defect in the cervical third of the child's primary tooth was considered unlikely.

Parafunctional placement of FBs by children and juveniles within the oral cavity should not be underestimated, as besides the direct involvement of the oral tissues, aspiration may affect more critical areas of the human body, including arteries, intracranial or pre-vertebral space [2]. A previous publication underlines that a FB aspiration could be a major cause of accidental death in children less than one year of age, also being the cause of death in $7 \%$ of children less than 4 years-old [24].
Tracheobronchial FB aspiration is a relatively frequent paediatric emergency, as well as a cause of substantial morbidity and mortality, especially in preschool children [24]. Button batteries are the most dangerous $\mathrm{FB}$ to be ingested, potentially causing lethal haemorrhage [25].

\section{CONCLUSIONS}

Accidental implantation of a foreign body in the oral soft and, less commonly, hard tissues may be a common phenomenon in children. However, the occurrence of a foreign object completely surrounding the cervix of a tooth is quite unusual. Herein, we presented such a rare case emphasizing the diagnostic challenges and management difficulties that may be encountered.

\section{ACKNOWLEDGMENTS AND DISCLOSURE STATEMENTS}

The authors would like to thank Dr. Vasileios Ionas Theofilou (Department of Oral Medicine \& Pathology and Hospital Dentistry, School of Dentistry, National and Kapodistrian University of Athens, Athens, Greece) for his valuable contribution to this study.

The authors report no conflicts of interest related to this study.

The authors did not receive support from any organization for the submitted work.

\section{REFERENCES}

1. French MA, Lorenzoni G, Purnima, Azzolina D, Baldas S, Gregori D, Gulati A. Foreign Body injuries in children in India: Recommendations for prevention from a comparative analysis with international experience. Int J Pediatr Otorhinolaryngol. 2019 Sep;124:6-13. [Medline: 31151032] [doi: 10.1016/j.ijporl.2019.05.020]

2. Inoue N. Oral injuries in children presenting to a Japanese pediatric emergency room. Pediatr Int. 2017 Jul;59(7): 826-830. [Medline: 28419671] [doi: 10.1111/ped.13299]

3. Mahesh C, Animireddy D, Mettu S, Kulkarni M. An Unexpected Encounter with Foreign Body in the Primary Teeth and Its Management. Int J Appl Basic Med Res. 2018 Jul-Sep;8(3):181-183. [Medline: 30123750] [PMC free article: 6082006] [doi: 10.4103/ijabmr.IJABMR_264 17]

4. Orengul AC, Tarakcioglu MC, Gormez V, Akkoyun S, Zorlu A, Áliyeva N, Uzuner S, Caliskan Y, Bikmazer A. Duration of Breastfeeding, Bottle-Feeding, and Parafunctional Oral Habits in Relation to Anxiety Disorders Among Children. Breastfeed Med. 2019 Jan/Feb;14(1):57-62. [Medline: 30412418] [doi: 10.1089/bfm.2018.0013]

5. Rocha AC, Bernabé DG, Amato Filho G, Guimarães Júnior J, Machado GG. Foreign body in the hard palate of children and risk of misdiagnosis: report of 3 cases. J Oral Maxillofac Surg. 2009 Apr;67(4):899-902. [Medline: 19304054] [doi: 10.1016/j.joms.2008.07.008]

6. Jayasuriya NSS, Karunathilaka PRCL, Wijekoon P. An unusual foreign object mimicking an odontoma in a patient with cleft alveolus: a case report. J Med Case Rep. 2017 Sep 26;11(1):279. [Medline: 28946895] [PMC free article: 5613624] [doi: 10.1186/s13256-017-1433-x]

7. Younessi OJ, Alcaino EA. Impalement injuries of the oral cavity in children: a case report and survey of the literature. Int J Paediatr Dent. 2007 Jan;17(1):66-71. [Medline: 17181582] [doi: 10.1111/j.1365-263X.2006.00765.x]

8. Gujjar KR, Algali G, Omar SM, Amith HV, Anegundi RT. Foreign bodies in primary molars: a report of 2 cases. J Dent Child (Chic). 2012 Jan-Apr;79(1):40-3. [Medline: 22449509] 
9. Katge F, Mithiborwala S, Pammi T. Incidental radiographic discovery of a screw in a primary molar: an unusual case report in a 6 year old child. Case Rep Dent. 2013;2013:296425. [Medline: 23878747] [PMC free article: 3710607] [doi: $10.1155 / 2013 / 296425$ ]

10. Gale S, Hall E, Bhujel N, McKaig S. Common things are common: a case series of oral foreign bodies in paediatric patients. Dent Update. 2009 Jan-Feb;36(1):53-4, 57-8. [Medline: 19294836] [doi: 10.12968/denu.2009.36.1.53]

11. Leith R, O’Connell AC. A foreign body in disguise. Eur Arch Paediatr Dent. 2013 Oct;14(5):359-62. [Medline: 23801078] [doi: $10.1007 / \mathrm{s} 40368-013-0060-5]$

12. Azodo CC, Erhabor P, Chukwumah NM, Ogordi P. Intraoral foreign body: A case report and review of literature. Indian J Multidiscip Dent. 2016 Jan;5(2):97-9. [doi: 10.4103/2229-6360.175031]

13. Imai H, Kubo S, Sasaki J, Shintani S. Marginal periodontitis with alveolar bone loss in lower deciduous incisor due to drinking straw-like plastic tube: Three case reports. Pediatric Dental Journal. 2013 Jul;22(1):84-9. [doi: 10.1016/S0917-2394(12)70257-4]

14. Bergantin BTP, Rios D, Oliveira DSB, Júnior ESP, Hanemann JAC, Honório HM. Localized Bone Loss Resulted from an Unlikely Cause in an 11-Year-Old Child. Case Rep Dent. 2018 Jul 8;2018:3484513. [Medline: 30073098] [PMC free article: 6057407$]$ [doi: $10.1155 / 2018 / 3484513]$

15. Gordon SC, Daley TD. Foreign body gingivitis: clinical and microscopic features of 61 cases. Oral Surg Oral Med Oral Pathol Oral Radiol Endod. 1997 May;83(5):562-70. [Medline: 9159816] [doi: 10.1016/S1079-2104(97)90121-9]

16. Al-Qutub MN. Orthodontic elastic band-induced periodontitis - A case report. Saudi Dent J. 2012 Jan;24(1):49-53. [Medline: 23960528] [PMC free article: 3723258] [doi: 10.1016/i.sdentj.2011.03.004]

17. Leider AS, Garbarino VE. Generalized hypercementosis. Oral Surg Oral Med Oral Pathol. 1987 Mar;63(3):375-80. [Medline: 3473365] [doi: 10.1016/0030-4220(87)90210-6]

18. Bürklein S, Jansen S, Schäfer E. Occurrence of hypercementosis in a German population. J Endod. 2012 Dec;38(12): 1610-2. [Medline: 23146646] [doi: 10.1016/i.joen.2012.08.012]

19. Eren Y, Erdal O, Serdar B, Emin KO, Enes G. Evaluation of the frequency and characteristics of hypercementosis in the turkish population with cone-beam computed tomography. Niger J Clin Pract. 2017 Jun;20(6):724-728. [Medline: 28656927] [doi: 10.4103/1119-3077.183254]

20. de La Dure-Molla M, Philippe Fournier B, Berdal A. Isolated dentinogenesis imperfecta and dentin dysplasia: revision of the classification. Eur J Hum Genet. 2015 Apr;23(4):445-51. [Medline: 25118030] [PMC free article: 4666581] [doi: 10.1038/ejhg.2014.159]

21. Witkop CJ Jr. Manifestations of genetic diseases in the human pulp. Oral Surg Oral Med Oral Pathol. 1971 Aug;32(2): 278-316. [Medline: 4327157] [doi: 10.1016/0030-4220(71)90232-5]

22. Carroll MK, Duncan WK, Perkins TM. Dentin dysplasia: review of the literature and a proposed subclassification based on radiographic findings. Oral Surg Oral Med Oral Pathol. 1991 Jul;72(1):119-25. [Medline: 1891231] [doi: 10.1016/0030-4220(91)90202-N]

23. Vieira AR, Lee M, Vairo F, Loguercio Leite JC, Munerato MC, Visioli F, D’Ávila SR, Wang SK, Choi M, Simmer JP, Hu JC. Root anomalies and dentin dysplasia in autosomal recessive hyperphosphatemic familial tumoral calcinosis (HFTC). Oral Surg Oral Med Oral Pathol Oral Radiol. 2015 Dec;120(6):e235-9. [Medline: 26337219] [PMC free article: 4640955] [doi: 10.1016/j.0000.2015.05.006]

24. Brkic F, Umihanic S, Altumbabic H, Ramas A, Salkic A, Umihanic S, Mujic M, Softic L, Zulcic S. Death as a Consequence of Foreign Body Aspiration in Children. Med Arch. 2018 Jun;72(3):220-223. [Medline: 30061771] [PMC free article: 6021165 ] [doi: 10.5455/medarh.2018.72.220-223]

25. Leinwand K, Brumbaugh DE, Kramer RE. Button Battery Ingestion in Children: A Paradigm for Management of Severe Pediatric Foreign Body Ingestions. Gastrointest Endosc Clin N Am. 2016 Jan;26(1):99-118. [Medline: 26616899] [PMC free article: 5425245] [doi: 10.1016/j.giec.2015.08.003]

\section{To cite this article:}

Papageorgiou N, Pettas E, Georgaki M, Nikitakis NG.

"Ring-Like Mass" Surrounding the Cervix of a Primary Incisor. Report of a Challenging Case

J Oral Maxillofac Res 2021;12(4):e5

URL: http://www.ejomr.org/JOMR/archives/2021/4/e5/v12n4e5.pdf

doi: $10.5037 /$ jomr.2021.12405

Copyright (C) Papageorgiou N, Pettas E, Georgaki M, Nikitakis NG. Published in the JOURNAL OF ORAL \& MAXILLOFACIAL RESEARCH (http://www.ejomr.org), 31 December 2021.

This is an open-access article, first published in the JOURNAL OF ORAL \& MAXILLOFACIAL RESEARCH, distributed under the terms of the Creative Commons Attribution-Noncommercial-No Derivative Works 3.0 Unported License, which permits unrestricted non-commercial use, distribution, and reproduction in any medium, provided the original work and is properly cited. The copyright, license information and link to the original publication on (http://www.ejomr.org) must be included. 